\title{
Wear Mechanisms of Hydrogenated DLC in Oils Containing MoDTC
}

\author{
Shahriar Kosarieh $^{1}$ (D) Ardian Morina ${ }^{1} \cdot$ Jonathan Flemming $^{2} \cdot$ Emmanuel Lainé $^{2}$. \\ Anne Neville ${ }^{1}$
}

Received: 1 April 2016/Accepted: 10 August 2016/Published online: 26 August 2016

(c) The Author(s) 2016. This article is published with open access at Springerlink.com

\begin{abstract}
Diamond-Like Carbon (DLC) coatings are well known for offering excellent tribological properties. They have been shown to offer low friction and outstanding wear performance in both dry and lubricated conditions. Application of these coatings for automotive components is considered as a promising strategy to cope with the emerging requirements regarding fuel economy and durability. Commercially available oils are generally optimised to work on conventional ferrous surfaces and are not necessarily effective in lubricating non-ferrous surfaces. Recently, the adverse effect of the Molybdenum DialkyldithioCarbamate (MoDTC) friction modifier additive on the wear performance of the hydrogenated DLC has been reported. However, the mechanisms by which MoDTC imposes this high wear to DLC are not yet well understood. A better understanding of DLC wear may potentially lead to better compatibility between DLC surfaces and current additive technology being achieved. In this work, the wear properties of DLC coatings in the DLC/cast iron (CI) system under boundary lubrication conditions have been investigated to try to understand what appears to be a tribocorrosion-type process. A pin-on-plate tribotester was used to run the experiments using High Speed Steel (HSS) plates coated with 15 at.\% hydrogenated DLC (a-C:15H) sliding against $\mathrm{CI}$ pins or ceramic balls. The lubricants used in this study are typical examples of the same fully formulated oil with and without ZDDP. The friction and wear responses of the fully
\end{abstract}

Shahriar Kosarieh

S.kosarieh@leeds.ac.uk

1 Institute of Functional Surfaces (iFS), School of Mechanical Engineering, University of Leeds, Leeds LS2 9JT, UK

2 Infineum UK Ltd., Milton Hill, Steventon, Oxfordshire OX13 6BB, UK formulated oils are discussed in detail. Furthermore, Optical Microscopy (OM) and Scanning Electron Microscopy (SEM), Energy-Dispersive X-ray spectroscopy (EDX), Focused Ion Beam (FIB) and Transmission Electron Microscopy (TEM) were used to observe the wear scar and propose wear mechanisms. The X-ray Photoelectron Spectroscopy (XPS) analysis was performed on the tribofilms to understand the tribochemical interactions between oil additives and the DLC coating. Nano-indentation analysis was conducted to assess potential structural modifications of the DLC coating. Coating hardness data could provide a better insight into the wear mode and failure mechanism of such hard coatings. Given the obtained results, the wear behaviour of the hydrogenated DLC coating was found to depend not only on the presence of ZDDP in the oil formulation but also on the counterpart type. This study revealed that the steel counterpart is a critical component of the tribocouple leading to MoDTC-induced wear of the hydrogenated DLC.

Keywords Diamond-Like Carbon (DLC) coatings - Wear . MoDTC $\cdot$ Fully formulated oils $\cdot$ ZDDP $\cdot$ Wear mechanisms $\cdot$ Friction

\section{Introduction}

It has been recognized that coating the surface of automotive components with Diamond-Like Carbon (DLC) is a promising strategy to deal with the emerging challenges faced by automotive industries. DLC coatings provide exceptional properties not only by offering low friction but also by exhibiting excellent wear resistance. Low friction can improve fuel economy, and low wear will increase the durability of engine components. Current additive technology is generally optimised to work on ferrous surfaces, 
and in the current and near future market, it is unlikely that an optimised oil for DLC only will be brought to the market. However, a better understanding of the mechanism by which a non-ferrous materials interact with a variety of lubricant additives may potentially lead to lubricant additive solutions being tailored for DLC surfaces in the future.

Molybdenum Dithiocarbamate (MoDTC) is a wellknown friction modifier, used for ferrous surfaces. Having low shear strength, $\mathrm{MoS}_{2}$ low-friction platelets, derived from MoDTC decomposition, provide low friction at the tribological contacts in boundary lubrication conditions [1-3]. Commonly used lubricant additives are designed to form tribofilms on ferrous-based surfaces. It is, therefore, essential to optimize coating and lubricant compatibility to enable additive solutions to be tailored to DLC surfaces.

Recently, the effect of MoDTC in increasing wear of the DLC coating in a DLC/steel contact has been reported by the current authors and others [4-13]. Different mechanisms by which lubrication by MoDTC leads to high wear to tribological systems including DLC have been proposed. Reaction of MoDTC-derived $\mathrm{MoO}_{3}$ with the DLC coating [5], graphitization of the DLC followed by the formation of hard Mo compounds on the DLC/CI interface [6] and the role of the counterpart in a "pro-wear process" [11] are some of the potential mechanisms for the occurrence of this phenomenon. Based on the published literature [4-13], it appears that MoDTC-derived products are key to this detrimental effect and that the type of counterpart may also play a part in high wear of DLC imposed by MoDTC. However, the origin of MoDTC-induced wear of DLC and the mechanisms by which the type of counterpart could affect this wear are not fully understood.

In our recent work [14], it was seen that fully formulated oils blended with a low concentration of Mo-FM (40 ppm of the molybdenum-based friction modifier) did not offer any friction reduction. However, the wear performance was observed to be excellent using these oils. Increasing the Mo-FM level in the oil resulted in lower friction but higher wear of the DLC coating. Also, the positive effect of ZDDP additive on controlling this wear was evident [9]. However, it was not clear whether (a) friction reduction was due to high wear of the DLC coating or (b) MoDTC forms a low-friction tribofilm followed by interaction between MoDTC-derived products and the DLC surface, and thus induces high wear of the coating.

Engine components in a real engine should operate for hundreds of thousands of cycles before being replaced. This demand implies that coating the parts with DLC requires careful optimisation of DLC/lubricant to avoid early failure of the coated parts in use. The aim of this work was to characterize and understand the interactions between DLC and MoDTC under simplified boundary lubricated conditions. A parametric study was conducted to quantify the evolution of tribochemical reactions. The influence of test duration and counter-body material was investigated to understand the tribological performance of the DLC/MoDTC contacts.

\section{Experimental Details}

\subsection{Pin-on-Plate Tests}

Tests were conducted using a reciprocating pin-on-plate tribometer under boundary lubrication conditions. The samples were cleaned before the start of the test using acetone. The test temperature was set at $100{ }^{\circ} \mathrm{C}$, and the contact point of the plate and the counterpart (CI pin/ceramic ball) was lubricated under a static volume of oil ( $3 \mathrm{ml}$ ). The average linear speed was $20 \mathrm{~mm} / \mathrm{s}$ (stroke frequency of $1 \mathrm{~Hz}$ ). To provide an initial Hertzian contact pressure of $0.7 \mathrm{GPa}$, a load of $390 \mathrm{~N}$ was used for the DLC/CI contacts. Towards the end of the study, some tests were done to assess the role of the counterpart on the DLC wear and in these tests, $13 \mathrm{~N}$ was used for DLC/ceramic couples. Both resemble a pressure range to a cam/follower contact in a gasoline engine. The duration of the tests was 6, 12 and $20 \mathrm{~h}$ for the DLC/CI and $20 \mathrm{~h}$ for the DLC/ ceramic system, and the friction force data were recorded every minute. For a more precise evaluation of the friction performance, each type of test was repeated at least three times, and the results were found to be repeatable.

\subsection{Materials}

Tests were carried out in the pin-on-plate tribotester using Cast Iron (CI) pins/ceramic balls and coated High Speed Steel (HSS) M2 Grade steel plates. The dimensions of the CI pin were $20 \mathrm{~mm}$ in length, the diameter of $6 \mathrm{~mm}$ and the ends of the pins had a $40 \mathrm{~mm}$ radius of curvature. The geometry of the plate was $15 \mathrm{~mm} \times 6 \mathrm{~mm} \times 3 \mathrm{~mm}$. The physical properties of the substrate, coatings and counterparts are given in Table 1.

\subsection{Lubricants}

The two lubricants used in this study are typical examples of the same fully formulated oil with and without ZDDP. Both lubricants contained MoDTC-type friction modifier (Mo-FM). Also, Organic Friction Modifier (OFM), detergent, dispersant and antioxidant were present in all of the lubricants. The key additive components in each oil are shown in Table 2.

Considering load, material and lubricant properties, the film thickness and the lambda ratio were calculated using equations Eqs. 1 and 2, respectively. $h_{\text {min }}$, minimum film thickness, is numerically defined as $[15,16]$ : 
Table 1 Physical properties of plates (substrate/coatings) and counterpart materials

\begin{tabular}{|c|c|c|c|c|}
\hline $\begin{array}{l}\text { Properties of coating and other } \\
\text { related materials }\end{array}$ & Ferrous material & & Ceramic ball & DLC coating \\
\hline Specification & HSS M2 Grade & Cast iron BS1452 & $\mathrm{Si}_{3} \mathrm{~N}_{4}$ & $\mathrm{a}-\mathrm{C}: 15 \mathrm{H}^{\mathrm{a}}$ \\
\hline Hardness & $8.0 \mathrm{GPa}$ & $4.0-4.5 \mathrm{GPa}$ & 14-17 GPa & $17.0 \mathrm{GPa}$ \\
\hline Reduced Young's modulus & $218 \mathrm{GPa}$ & $134 \mathrm{GPa}$ & 300-320 Gpa & $190 \mathrm{GPa}$ \\
\hline Roughness, $\mathrm{R}_{\mathrm{q}}$ & $0.04-0.06 \mu \mathrm{m}$ & $0.07-0.09 \mu \mathrm{m}$ & $0.02-0.0025 \mu \mathrm{m}$ & $0.04-0.06 \mu \mathrm{m}$ \\
\hline Composition/Coating thickness & $\begin{array}{l}\text { C } 0.64 \%, \text { Si } 0.55 \% \text {, } \\
\text { Cr } 1.57 \% \text {, and Mn } 0.49 \%\end{array}$ & $\begin{array}{l}\text { C } 3.0 \% \text {, Si } 2.0 \% \text {, } \\
\text { Mn } 0.4 \%, \text { Cr } 0.1 \%, \text { Cu } 0.3 \%\end{array}$ & $90 \% \mathrm{Si}_{3} \mathrm{~N}_{4}$ & $2-4 \mu \mathrm{m}$ coating \\
\hline
\end{tabular}

${ }^{a}$ Commercial coatings obtained from Oerlikon Balzers Ltd., UK

Table 2 Lubricant components

\begin{tabular}{lllll}
\hline Lubricants & Annotations & ZDDP & Mo $(\mathrm{ppm})$ & $P(\mathrm{ppm})^{*}$ \\
\hline Fully formulated oils & Oil+ & + & 600 & 750 \\
& Oil- & - & 600 & -
\end{tabular}

* All oils contain organic friction modifier (OFM), detergent, dispersant, and antioxidant

$\frac{h_{\min }}{R^{\prime}}=3.63\left(\frac{U \eta_{0}}{E^{\prime} R^{\prime}}\right)^{0.68}\left(\alpha E^{\prime}\right)^{0.49}\left(\frac{W}{E^{\prime} R^{\prime 2}}\right)^{-0.073}\left(1-e^{-0.68 k}\right)$

where $\eta_{0}$ is the dynamic viscosity at atmospheric pressure of the lubricant $\left(4.03 \times 10^{3} \mathrm{~Pa} \mathrm{~s}\right), \alpha$ is the viscosity-pressure coefficient $\left(1.1 \times 10^{-8} \mathrm{~Pa}^{-1}\right), R^{\prime}$ is the reduced radius of curvature $(20 \mathrm{~mm}$ for the $\mathrm{CI} \mathrm{pin} / 3 \mathrm{~mm}$ for the ceramic ball), $U$ is the entraining surface velocity $(20 \mathrm{~mm} / \mathrm{s}), W$ is the normal load $(390 \mathrm{~N} / 13 \mathrm{~N})$, and $E^{\prime}$ is the reduced Young's modulus. The dynamic viscosity and viscositypressure coefficient were measured at $100{ }^{\circ} \mathrm{C}$. The lambda ratio is:

$\lambda=\frac{h_{\min }}{\sqrt{R_{q_{1}}^{2}+R_{q_{2}}^{2}}}$

where $R_{q_{1}}$ is the roughness of the coated plate and $R_{q_{2}}$ is the roughness of the pin end. The calculation gives the lambda ratio well under unity $(0.002$ for the DLC/CI and 0.02 for the DLC/ceramic) implying that lubrication for both the DLC/CI and DLC/ceramic systems were in boundary regime.

\subsection{Surface Analysis}

In this study, all coating wear analyses (Optical Microscope, SEM/EDX and FIB/TEM) and Nano-indentation analysis were performed to characterize DLC wear and/or structural modification/graphitisation of the coating. Therefore, before these analyses, in order to remove any physisorbed tribofilm formed on the wear scar, all samples were cleaned in acetone in an ultrasonic bath for at least 45 min. Removal of the tribofilm was confirmed by the TEM analysis of the DLC coatings. A different sample cleaning process was used for tribofilm chemical characterization with XPS. Therefore, prior to the XPS analysis, any residual oil and/or contaminants were removed only by soaking the samples in $n$-heptane for $10 \mathrm{~s}$.

\subsubsection{Wear Measurements}

Wear of the plates (where measurable) was measured using a Veeco WYKO White Light Interferometer (NT3300S model) which had the capability to measure wear scar depth, cross-sectional area and wear volume. In this study, the cross-sectional areas of the wear scars were obtained using Vision64 software in at least in three different positions across the wear track. The average value of the cross-sectional area was multiplied by the stroke length which gave the wear loss volume of the plate. The software was also able to provide the wear volume directly but levelling the surface made it difficult to get the correct wear volume. The specific wear coefficients were calculated using the Archard wear equation:

$K_{i}=\frac{V_{i}}{F \times S}$

where $F$ is the normal load $(\mathrm{N}), S$ the sliding distance $(\mathrm{m})$, $V_{i}$ the wear volume $\left(\mathrm{m}^{3}\right), K_{i}$ the dimensional wear coefficient and index $i$ identifies the surface considered.

\subsubsection{Coating Wear Analysis}

In this study, a Zeiss EVO MA15 Variable Pressure SEM was used to investigate the mechanism of wear and the durability of the coatings. It was integrated with an Oxford Instruments Energy-Dispersive X-ray (EDX) analysis system. In this study, the EDX analysis was used to provide information about the durability of the coating. EDX 
mapping obtained within the wear tracks showed the presence of carbon (C) and chromium ( $\mathrm{Cr}$ ). Chromium comes from the underlying $\mathrm{CrN} / \mathrm{CrC}$ intermediate layer of the DLC coating. This could be used as a qualitative analysis of the extent of the coating wear. The higher the chromium intensity in the EDX maps, the greater the removal of coating thickness due to wear (Fig. 1).

Field Emission Gun Scanning Electron Microscope (FEGSEM) with precise Focused Ion Beam (FIB) was used to expose cross sections of the DLC samples. Milling was performed at $30 \mathrm{kV}$ and beam currents between 5 and $0.1 \mathrm{nA}$. A final cleaning step was performed at $5 \mathrm{kV}$ and with a beam current of 29 pA. Cross sections were then removed in situ using a Kleindiek micromanipulator and attached to a TEM support grid ready for analysis. Agar High-Resolution Sputter coater was used to sputter a platinum coating to the surface before a thicker $1-\mu \mathrm{m} P t$ layer was applied by a gaseous injection system. This was done to protect the surface from the ion beam. To get a high-resolution view of the cross-sectional area of the DLC-coated samples, Transmission Electron Microscopy (TEM) analyses were performed. TEM characterisation was carried out using a Philips CM200 FEGTEM operated at $197 \mathrm{kV}$ and fitted with a Gatan GIF200 imaging filter. The TEM high-resolution images were taken to characterise the DLC coatings before the tribo-test and to provide information about the extent of wear post-tribo-tests.

\subsubsection{Nano-Indentation Analysis}

Mechanical properties of the coatings were obtained by nano-scale indentation using a Micro Materials Limited NanoTestTM Platform One device. The indentations were performed in a controlled environment temperature of $25{ }^{\circ} \mathrm{C}$, using a Berkovich-type indenter. The Berkovich

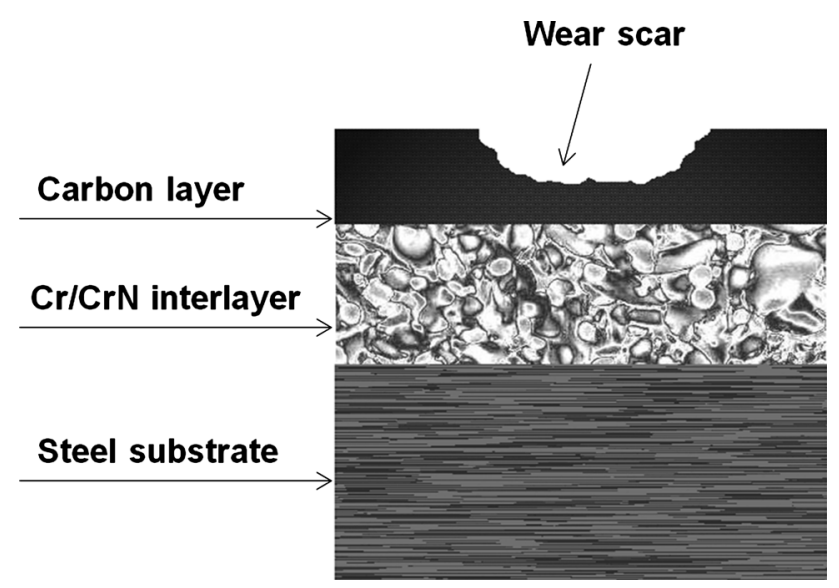

Fig. 1 Schematic diagram showing the cross section of the DLCcoated plate. The concentration of $\mathrm{Cr}$, detected by EDX, is higher inside the wear track compared to outside indenter used in this study had a three-faced pyramid and a typical tip radius of $100-500 \mathrm{~nm}$. As a result of the measurement, the force-displacement curve was produced. By analysing the recorded results, mechanical properties such as hardness and modulus of elasticity were obtained.

A commonly used rule of thumb is to limit the indentation depth to less than $10 \%$ of the thickness of the coating to eliminate the "substrate effects" [17, 18]. Therefore, in this study, the indentation load was set at $5 \mathrm{mN}$, resulting in a maximum indentation depth of $80-120 \mathrm{~nm}$ in the coating (In this study the thickness of asdeposited DLC coating was about $2 \mu \mathrm{m}$ ). Loading and unloading were performed for $30 \mathrm{~s}$ with a $5 \mathrm{~s}$ hold at peak load. A thermal drift correction of $60 \mathrm{~s}$ at $90 \%$ unloading was used so that the material could settle within temperature variations caused by the indentation process. A standard indentation grid of four rows by three columns $(50 \mu \mathrm{m}$ spacing) was chosen and was applied to all samples. The indenter was tested regularly for accuracy using a standard silicon plate that has known hardness values.

\subsubsection{Chemical Analysis of the Tribofilms}

XPS analysis measurements were made on the tribofilm formed on the plate surfaces. This surface sensitive technique can analyse the very top layer of the surface $(5 \mathrm{~nm}$ depth). An area of $500 \mu \mathrm{m} \times 500 \mu \mathrm{m}$ in the wear scar of the plates was analysed using a monochromatized $\mathrm{Al} \mathrm{K}[\alpha]$ source in the XPS. The spatial mode was chosen to acquire all the spectra. The curves on the XPS peaks obtained from long scans were fitted using CasaXPS software [19], and the quantitative analyses of the peaks were performed using peak area sensitivity factors. The chemical species corresponding to each binding energy were found using a handbook of XPS [20]. The position of the C1s peak $(284.8 \mathrm{eV})$ was considered as the reference for charge correction. The peak area ratio, the difference between binding energies of the doublets, and Full-Width at HalfMaximum (FWHM) were constrained to provide the most appropriate chemical meaning. A linear background approximation was used to process the data in this study.

\section{Results}

\subsection{DLC/CI System}

In the first part of the study, experiments were carried out using CI pins and DLC-coated plates for different test duration. Tests were conducted for different time intervals to quantify the evolution of tribochemical reactions occurring in the DLC/CI contacts lubricated in oils containing MoDTC. 


\subsubsection{Friction Results}

A drop in friction was observed (Fig. 2) using both oils, but the addition of ZDDP to the oil (Oil+) resulted in higher friction values. Higher friction is consistent with what is seen in the literature for ZDDP-containing oils on steel surfaces [21]. Following long $(20 \mathrm{~h})$ tests, the friction response of the oils (see Fig. 2) was seen to vary with time. The friction coefficients, which initially dropped, started to rise again in the region of $10-12 \mathrm{~h}$ after the start of the tests. This increase of friction could be due to coating failure or/and its continuous wear. The changes in the interface due to wear could lead to the formation/depletion of the tribofilm on the interface. Thus, $12 \mathrm{~h}$ tests were conducted to provide a better understanding of friction behaviour and wear mechanisms of the oils on the DLC coating as a function of time. Also, $6 \mathrm{~h}$ tests were also conducted in the region where friction was still decreasing, and the coating was not suffering from severe wear which will be discussed later in this paper.

Figure 3 shows the average coefficient of friction for the last hour of the tests for different time intervals using both Oil+ and Oil-. Overall, friction values were higher for Oil+ for all the time intervals, as expected [21]. Based on

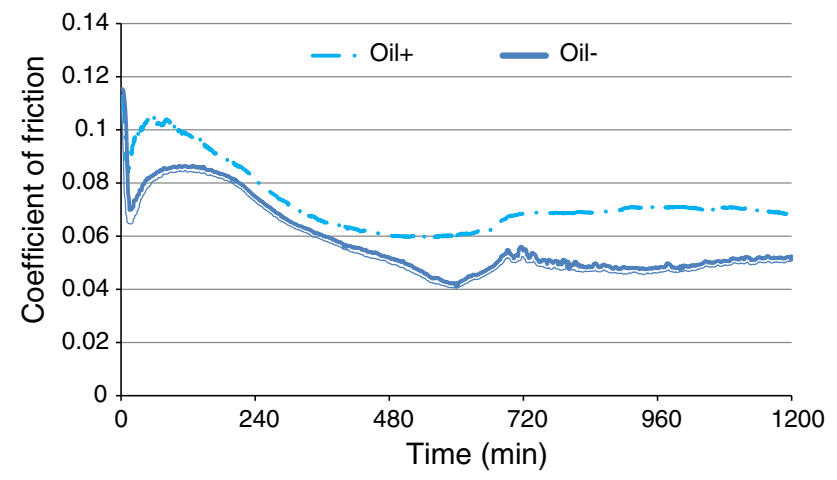

Fig. 2 Representative friction traces for Oil+ and Oil- oils over $20 \mathrm{~h}$ tribo-tests

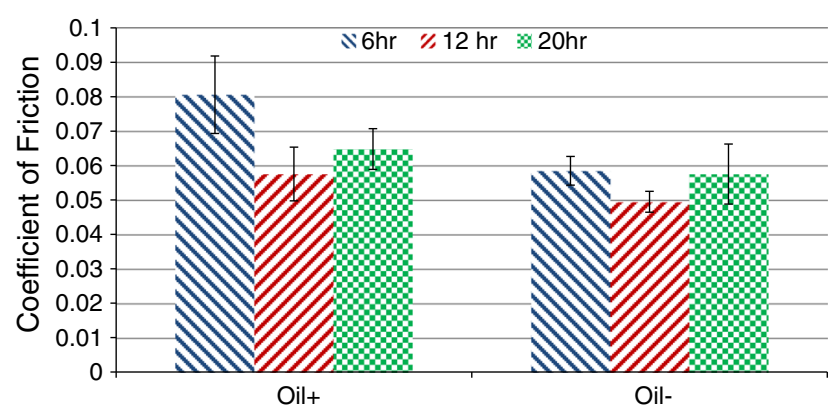

Fig. 3 Average coefficient of friction for the last hour of the tests as a function of oils at different time intervals for the DLC/CI system the friction results, it is evident that friction values were generally lower for $12 \mathrm{~h}$ tests than 20 and $6 \mathrm{~h}$ tribo-tests.

\subsubsection{Wear Results}

Figure 4 shows representative images of wear tracks on the DLC coating after 6,12 and $20 \mathrm{~h}$, respectively. Based on the optical images, the colour of the coatings was brighter inside the wear tracks than outside. This suggests that the underlying $\mathrm{Cr} / \mathrm{CrN}$ layers were exposed due to high wear. The average depth of the wear track $\left(h_{d}\right)$ of the DLC coating for the highest obtained wear, provided by Oil-, was approximately $0.15 \mu \mathrm{m}$ over $6 \mathrm{~h}$ test (see Fig. 4) while it increased to $1.06 \mu \mathrm{m}$ when the duration of the test was $20 \mathrm{~h}$.

The wear coefficients as a function of the test duration for the DLC/CI combination using the two oils are given in Fig. 5. For $6 \mathrm{~h}$ tests, the wear values for both oils were found to be relatively low. By increasing the test duration to 12 and $20 \mathrm{~h}$, the wear rates given by both oils rose. However, Oil- promotes a faster wear increase than Oil+. This could be due to the positive effect of ZDDP in the Oil+ formulation.

To verify the observations from the wear results and the optical microscope images, EDX was carried out inside the wear scar. The representative Secondary Electron (SE) images of a section of the DLC coating wear scar along with EDX mapping of carbon (C), chromium $(\mathrm{Cr})$ and iron (Fe) after 6, 12 and $20 \mathrm{~h}$ tribo-tests are shown in Fig. 6. In the case of Oil-, the chromium intensity increased inside the wear track (Fig. 6a, b), showing higher removal of the $\mathrm{C}$ layer of the coating after $6 \mathrm{~h}$ tests. This observation is in agreement with our obtained wear data and optical microscope observation where Oil- gave relatively higher wear to the DLC coating for $6 \mathrm{~h}$ tests. Fe was not detected using any of the oils confirming no delamination of the DLC coating after $6 \mathrm{~h}$ tribo-tests.

By increasing the test duration to $12 \mathrm{~h}$, the intensity of carbon peak detected with EDX decreased, and chromium increased inside the wear scar as compared to outside, indicating wear of the $\mathrm{C}$ layer. Chemical element mapping shown in Fig. 6 confirms the presented wear data in Fig. 4, in which Oil- gave higher wear to the DLC coating after $12 \mathrm{~h}$ tribo-tests. Fe was absent from all regions inside the wear scar indicating that no delamination of the coatings or/and iron transfer from the CI pin to the DLC coating has occurred after $12 \mathrm{~h}$ of the tests using both oils.

Increasing the test duration to $20 \mathrm{~h}$ resulted in a higher intensity of chromium inside the wear track than outside, implying wear of the coatings for both oils after $20 \mathrm{~h}$ tests. In contrast to the analysis of 6 and $12 \mathrm{~h}$ samples, iron was detected in the EDX map of the DLC plate after $20 \mathrm{~h}$ tribotest, when using the Oil- lubricant. This could be either due 
Fig. 4 Optical images of the wear scars formed on the DLCcoated plates using Oil+ and Oil-. The arrows on the images show sliding directions and $\mu$ and $H_{d}$ are the coefficient of friction and the average depth of the wear track, respectively

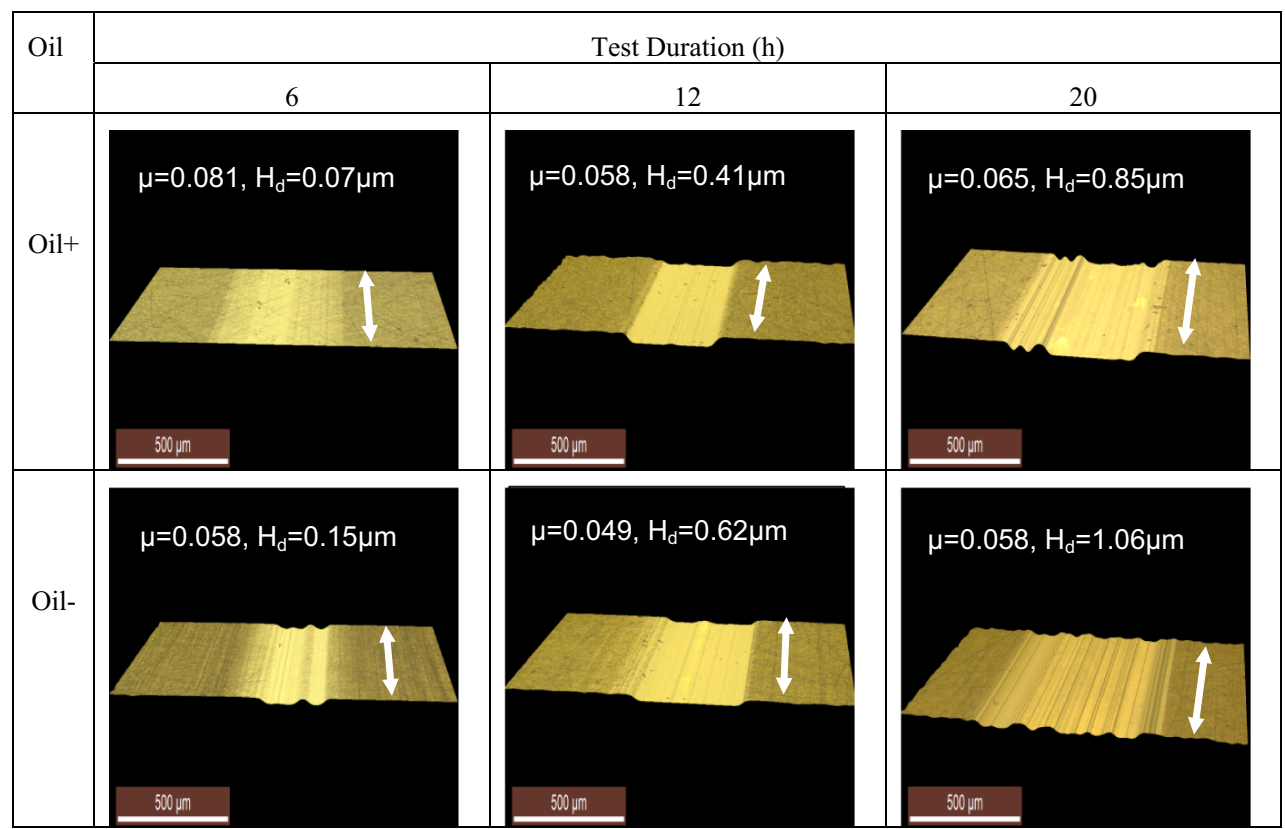

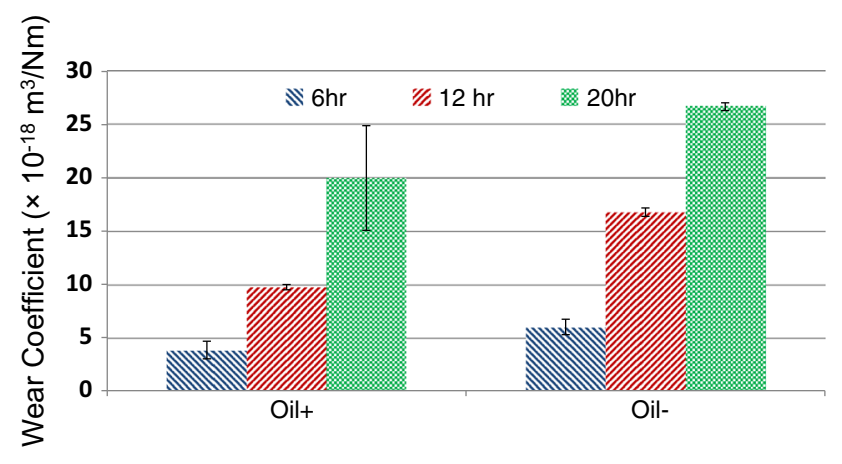

Fig. 5 Wear coefficient of DLC-coated plates as a function of oils at different time intervals for the DLC/CI system

to the exposed ferrous substrate (delamination or severe wear) or due to the decrease in the coating thickness (severe wear). Iron transfer from the pin to the plate can be excluded based on our previous work [9] which showed that the wear of the pin was not responsible for such high DLC wear.

For the DLC/CI contacts after $20 \mathrm{~h}$ tribo-tests, cross sections of a small area inside the DLC wear scar as well as the as-deposited DLC were exposed by FIB. Cross-sectional TEM images of the as-deposited DLC coating, worn DLC coating by Oil+ and worn DLC coating by Oil- are shown in Fig. 7.

Based on the TEM high-resolution images, the thickness of the as-deposited coating, including $\mathrm{CrC} / \mathrm{CrN}$ interlayer, was seen to be around $2 \mu \mathrm{m}$. It is also evident that using either Oil+ or Oil-, more than half of the top DLC layer (carbon layer) has been worn out after the $20 \mathrm{~h}$ tribological test (Fig. 7b, c). This is in agreement with the observations obtained from optical microscope, interferometer and EDX mapping which showed that the DLC coatings have undergone severe wear after $20 \mathrm{~h}$ tribo-tests. Apart from sputtered platinum films on top of the carbon layer (DLC layer), which was thicker on the DLC sample for Oil-, no sign of any other film was observed on the DLC coating using either oils (see Fig. 7), showing that cleaning the samples in an ultrasonic bath before the analysis led to the removal of any potential tribofilm formed on the DLC coating surface.

\subsubsection{Chemical Analysis of the Tribofilm}

3.1.3.1 Elemental Quantification XPS analysis was conducted to study the formed tribofilm on the DLC plates and their corresponding counterparts as a function of the test duration. Prior to the XPS analysis, any residual oil and/or contaminants were removed only by soaking the samples in $n$-heptane for $10 \mathrm{~s}$. The chemical quantification of the tribofilms formed on the DLC/CI tribocouple, for different test durations, are shown in Table 3. As expected, it is evident that oil additives were decomposed and formed a tribofilm on both the DLC and the CI pin counterpart. This could generally dominate the tribological performance of the DLC/CI system and durability/wear performance of the coatings in particular.

For 6 and $12 \mathrm{~h}$ tests, using both oils, the absence of a Fe $2 p$ peak in the tribofilm formed on the DLC coating indicates that no delamination of the coating occurred or/and that no iron coming from the pin wear particles participated in the tribofilm formation on the DLC surface. For $20 \mathrm{~h}$ tests, however, a Fe $2 p$ peak was detected in the Oil- DLC wear scar, in agreement with the EDX analysis of the same sample shown in Fig. 6. 


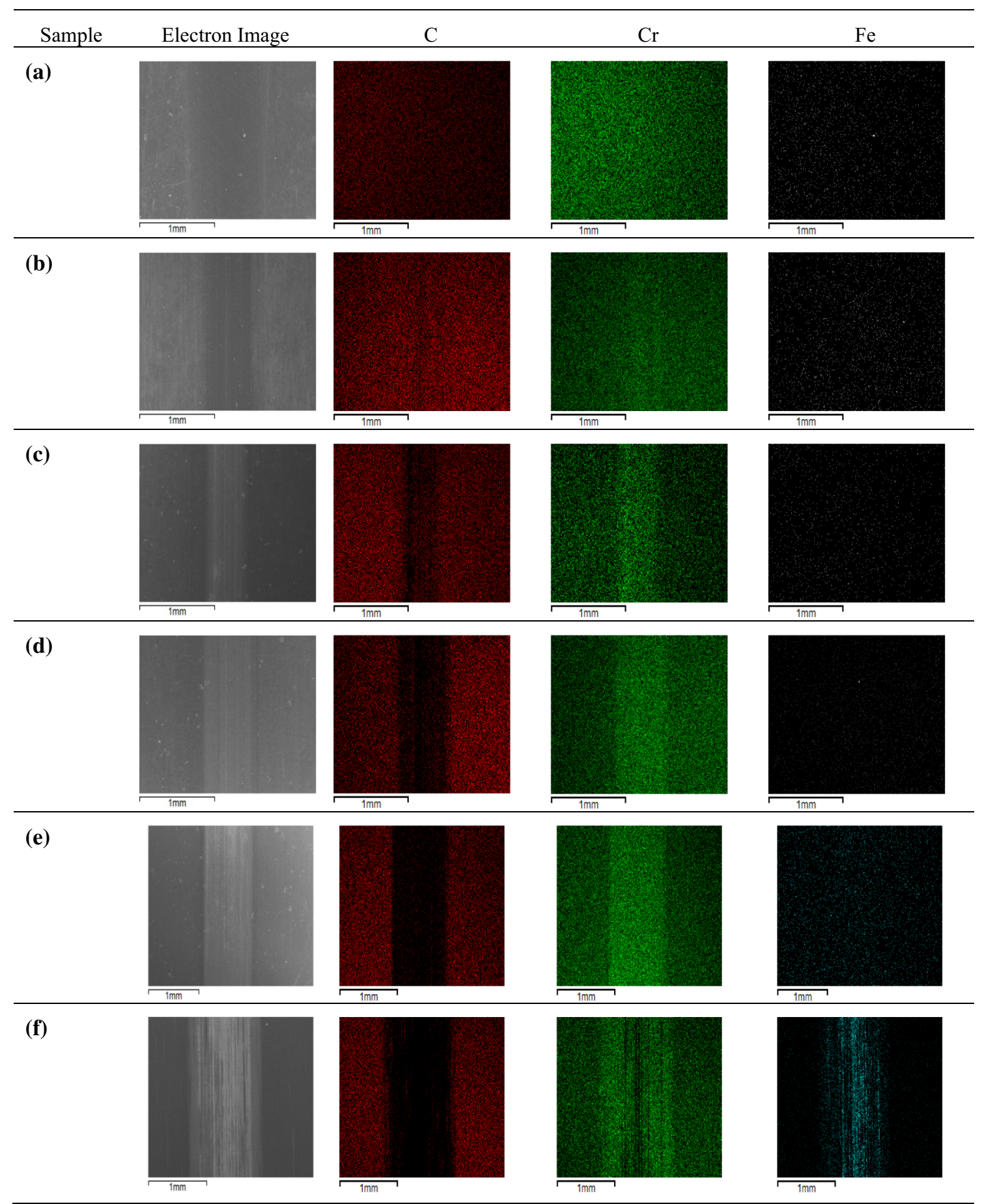

Fig. 6 SEM image of the DLC coating along with EDX mapping of the C, Cr and Fe atoms for: a Oil+ after 6 h, b Oil- after 6 h, c Oil + after $12 \mathrm{~h}, \mathbf{d}$ Oil- after $12 \mathrm{~h}$, e Oil + after $20 \mathrm{~h}$ and f Oil- after $20 \mathrm{~h}$ tribo-tests

\subsubsection{Anti-Wear Film Formation Figure 8 shows XPS} spectra of ZDDP-derived species ( $\mathrm{Zn} 2 \mathrm{p}$ and P 2p) formed on the DLC plate ( $a$ and $b$ ) and the CI pin ( $c$ and d) using Oil+ as a function of test duration. It is clear that using Oil+, irrespective of the duration of the tests, $\mathrm{Zn}$ phosphate and $\mathrm{ZnS} / \mathrm{ZnO}$ species were formed on both the DLC surface and CI pins. The only exception was the tribofilm which was formed on the CI pin after $6 \mathrm{~h}$ test using Oil+, which was mainly $\mathrm{Zn}-\mathrm{S}-\mathrm{O}$ compounds $(\mathrm{BE}=1023.15 \mathrm{eV})$. It is, therefore, evident that despite the high level of Mo-FM which was blended in the Oil+, formation of phosphate films on the surface was not deterred.

Nevertheless, ZDDP in Oil+ raised the friction values compared to Oil- (see Fig. 3). This could be due to the 


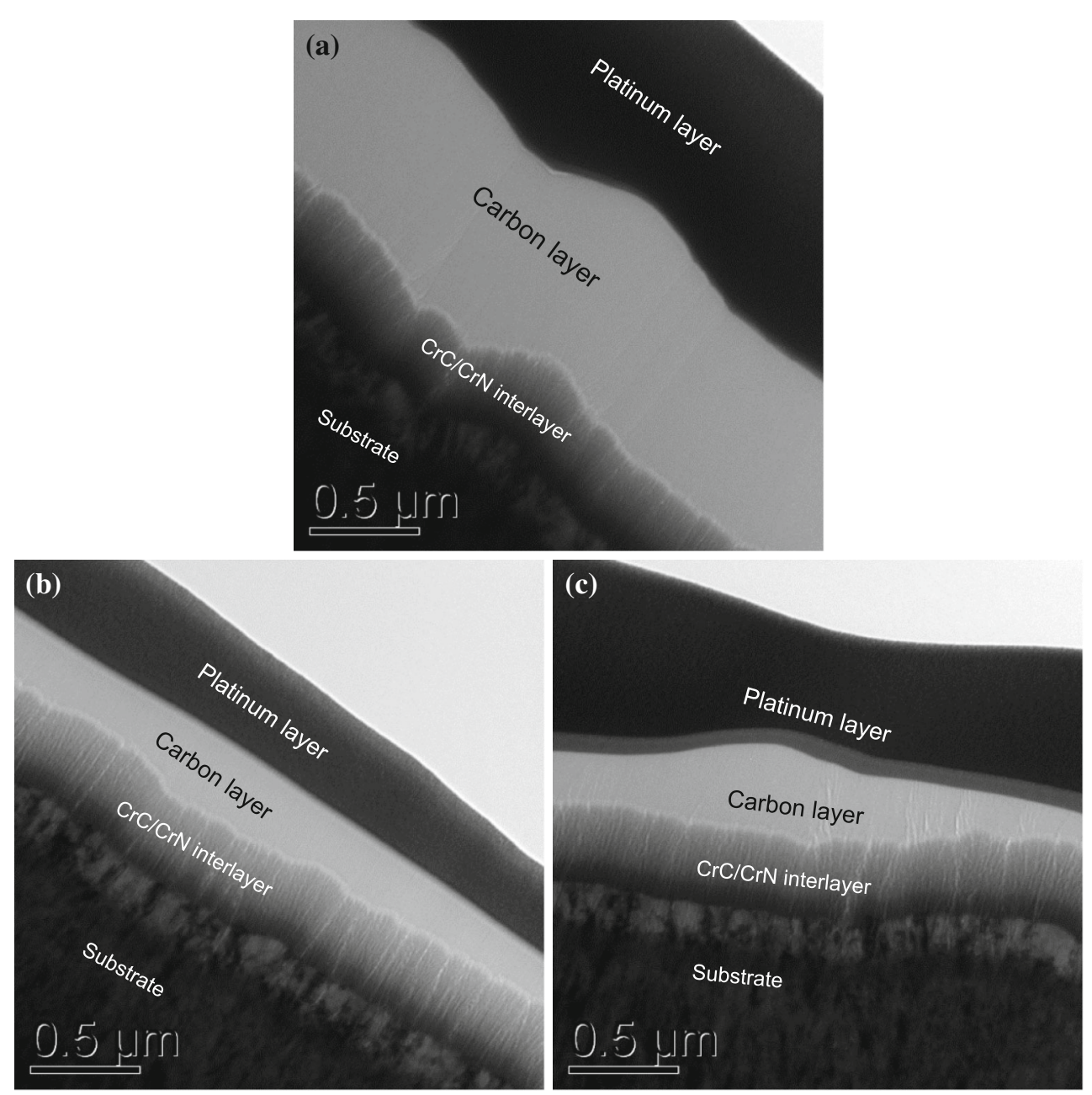

Fig. 7 TEM image of the: a as-deposited DLC coating, b worn DLC coating by Oil+ after $20 \mathrm{~h}$ DLC/CI tribo-tests and $\mathbf{c}$ worn DLC coating by Oil- after $20 \mathrm{~h} \mathrm{DLC/CI} \mathrm{tribo-tests}$

Table 3 XPS quantification of tribofilms for the DLC/CI system for: (a) Oil+ after $6 \mathrm{~h}$, (b) Oil- after $6 \mathrm{~h}$, (c) Oil+ after $12 \mathrm{~h}$, (d) Oil- after $12 \mathrm{~h}$, (e) Oil+ after $20 \mathrm{~h}$ and (f) Oilafter $20 \mathrm{~h}$ tribo-tests

\begin{tabular}{|c|c|c|c|c|c|c|c|c|c|c|}
\hline \multirow[t]{3}{*}{ Sample } & \multirow[t]{3}{*}{ Surface } & \multicolumn{9}{|c|}{ Elemental composition of Tribofilms (at.\%) } \\
\hline & & $\mathrm{Fe}$ & $\mathrm{O}$ & $\mathrm{P}$ & $\mathrm{Zn}$ & $\mathrm{C}$ & $\mathrm{Ca}$ & Mo & $\mathrm{N}$ & $\mathrm{S}$ \\
\hline & & $2 p$ & $1 \mathrm{~s}$ & $2 p$ & $2 p$ & $1 \mathrm{~s}$ & $2 p$ & $3 d$ & $1 \mathrm{~s}$ & $2 p$ \\
\hline \multirow[t]{2}{*}{ (a) } & Pin & 0.4 & 14.0 & 0.3 & 0.2 & 76.7 & 0.8 & 4.1 & 1.6 & 1.9 \\
\hline & Plate & 0.0 & 7.4 & 0.2 & 0.1 & 86.7 & 0.5 & 3.2 & 0.9 & 0.8 \\
\hline \multirow[t]{2}{*}{ (b) } & Pin & 0.2 & 13.7 & 0.0 & 0.0 & 69.2 & 1.6 & 11.9 & 2.3 & 1.2 \\
\hline & Plate & 0.0 & 6.3 & 0.0 & 0.0 & 89.5 & 0.5 & 2.0 & 1.0 & 0.7 \\
\hline \multirow[t]{2}{*}{ (c) } & Pin & 0.4 & 16.6 & 0.7 & 0.3 & 62.1 & 0.9 & 11.4 & 5.9 & 1.7 \\
\hline & Plate & 0.0 & 2.4 & 0.2 & 0.1 & 93.9 & 0.0 & 1.4 & 1.3 & 0.7 \\
\hline \multirow[t]{2}{*}{ (d) } & Pin & 0.5 & 18.2 & 0.0 & 0.0 & 52.9 & 1.5 & 17.0 & 7.9 & 1.8 \\
\hline & Plate & 0.0 & 2.9 & 0.0 & 0.0 & 93.8 & 0.3 & 1.4 & 1.1 & 0.5 \\
\hline \multirow[t]{2}{*}{ (e) } & Pin & 0.8 & 34.7 & 3.2 & 0.9 & 48.6 & 2.7 & 5.3 & 2.6 & 1.1 \\
\hline & Plate & 0.0 & 3.0 & 0.4 & 0.1 & 91.4 & 0.7 & 2.3 & 1.3 & 0.8 \\
\hline \multirow[t]{2}{*}{ (f) } & Pin & 0.9 & 21.0 & 0.0 & 0.0 & 63.2 & 2.0 & 7.8 & 4.0 & 1.1 \\
\hline & Plate & 0.3 & 9.1 & 0.0 & 0.0 & 76.5 & 1.6 & 6.9 & 4.1 & 1.4 \\
\hline
\end{tabular}


Fig. 8 XPS spectra of ZDDPderived species a $Z n 2 p$, b P $2 p$ formed on the DLC-coated plate and $\mathbf{c} \mathrm{Zn} 2 \mathrm{p}$ and $\mathbf{d} \mathrm{P} 2 \mathrm{p}$ formed on the CI pin using Oil+ as a function of test duration
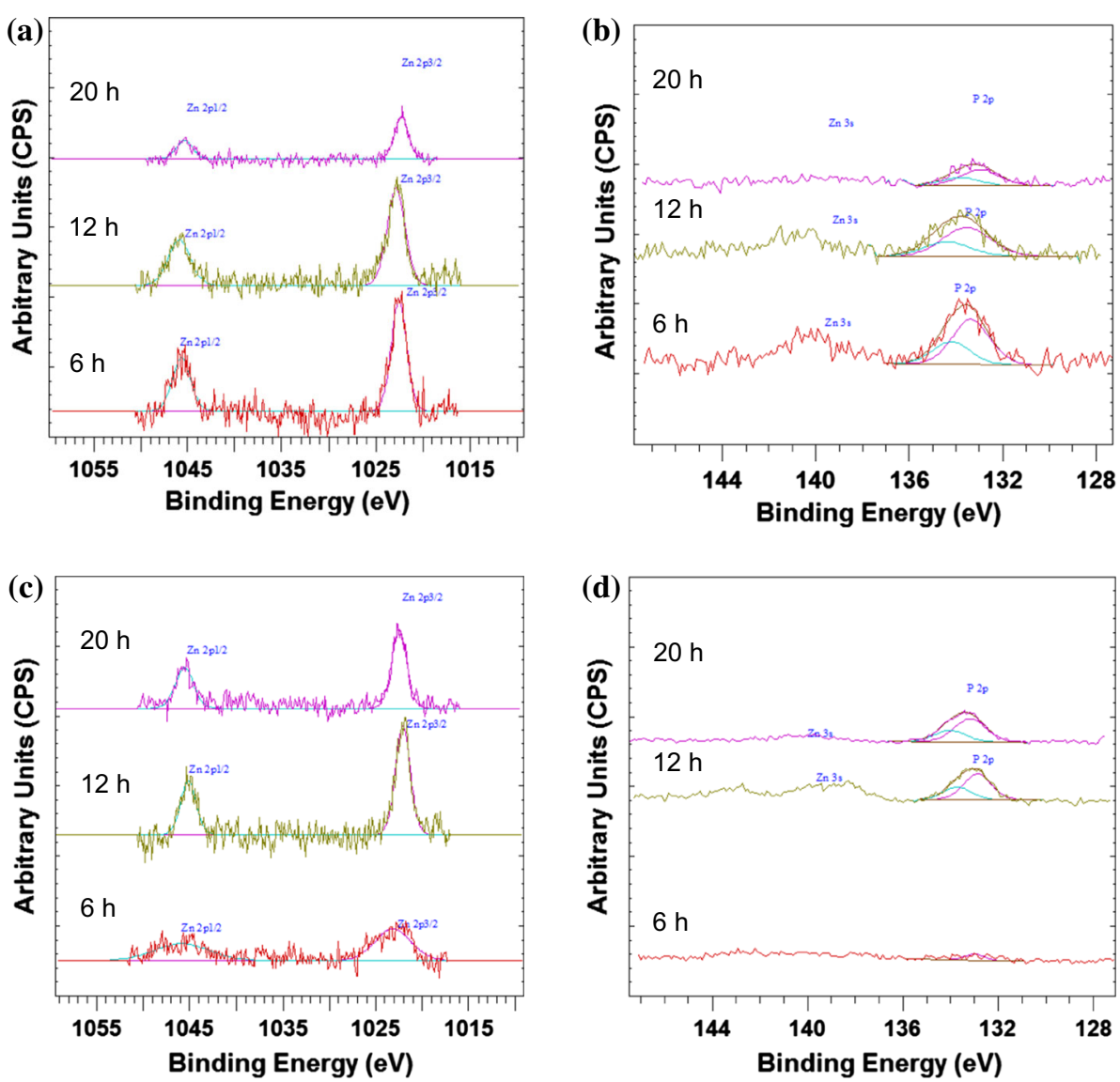

formation of pad-like ZDDP tribofilms in Oil+ [21]. In addition, irrespective of the test duration, wear was always lower in Oil+ than in Oil-, as shown in Fig. 5.

\subsubsection{Low-Friction Film Formation Tribofilm chemi-} cal element quantification shown in Table 3 confirms that a Mo-containing film is formed on both the DLC and the CI samples. However, the intensity of the Mo 3d XPS peak detected on DLC samples was significantly lower than on CI pin, making its deconvolution difficult. In any case, comparing the Mo $3 \mathrm{~d}$ peaks obtained from the CI counterparts is a good approach towards understanding the tribochemistry of the DLC/CI system. In general, more Mo was detected on the CI pins for $12 \mathrm{~h}$ tests than $6 \mathrm{~h}$ tests. This could justify the lower friction values obtained at $12 \mathrm{~h}$. The fitted Mo 3d peaks obtained from both oils formed on the pins after 6,12 and $20 \mathrm{~h}$ are shown in Fig. 9. Considering the binding energies of the $S 2 p$ (as Fig. 9 indicates), irrespective of the test duration, abrasive Mooxide species (e.g. $\mathrm{MoO}_{\mathrm{x}}$ ) as well as the low shear strength $\mathrm{MoS}_{2}$ were identified in the tribofilms formed on the CI pins. However, in general, $\mathrm{MoS}_{2}$ made a more significant contribution to the overall film formation. Mo-Oxide Species could be related to formation of Iron molybdates species. It has been previously shown that ferrous surfaces participate in the decomposition of MoDTC by reacting with the decomposition products to form $\mathrm{FeMoO}_{4}$ [22].

Higher intensity of the Mo detected is an indication of a more MoDTC-derived tribofilm on the wear scar. Therefore, it appears that the tribofilm formed from these oils were richer in Mo (mainly consisting of $\mathrm{MoS}_{2}$ ) after $12 \mathrm{~h}$, but that MoDTC-derived species were depleted in the tribofilm after $20 \mathrm{~h}$ test. Qualitative and quantitative features of the Mo XPS peaks seem to correlate with the friction results (see Fig. 3), where lower friction values corresponded to large $\mathrm{MoS}_{2}$ peak on the wear scar.

The fitted carbon peaks for the higher wearing oil (Oil-) in the tribofilm formed on both the CI pin and the DLC plate after 12-h test are shown in Fig. 10. It can be seen that only a minor portion of carbon on the DLC coating was oilderived oxygen-containing hydrocarbon species while a major part was detected to be pure carbon (graphitic) [20]. This could be due to the modification/graphitization of the DLC coating. High wear provided by the high Mo-FM concentration fully formulated oil resulted in transferring the DLC wear debris to the pin counterface. This is confirmed by the presence of graphitic carbon in the tribofilms formed on the CI pin. Furthermore, the higher detected oilderived hydrocarbon species on the CI pin could be due to the higher reactivity of the ferrous counterbody with the 
Fig. 9 Fitted Mo 3d peaks formed on the CI pins from a Oil- and $\mathbf{b}$ Oil+ as a function of test duration. The corresponding average steady state friction for each oil for all time intervals is also shown
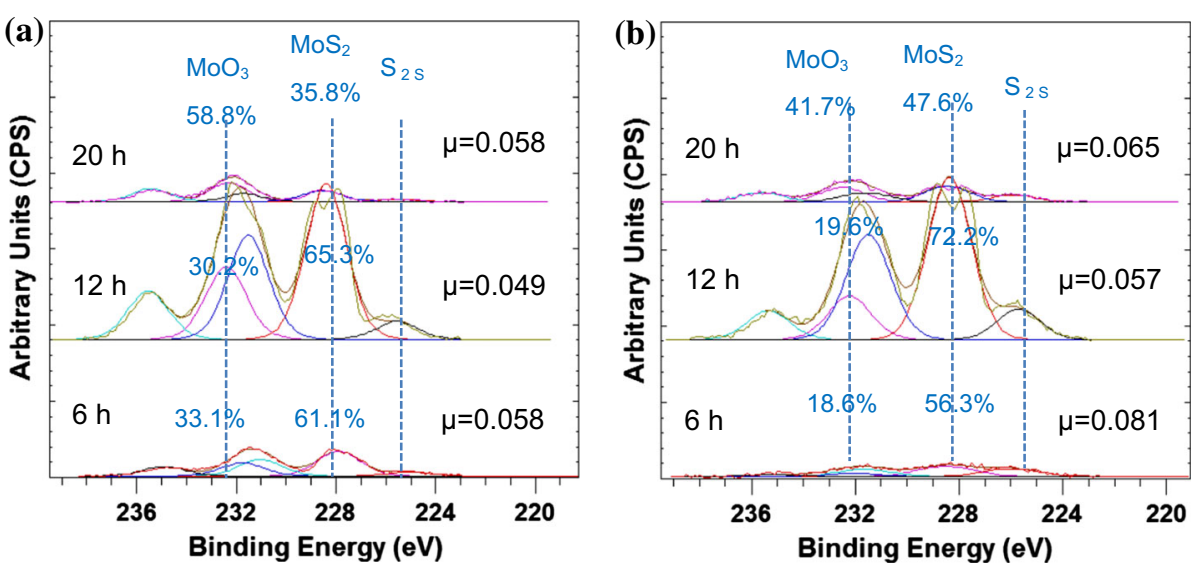

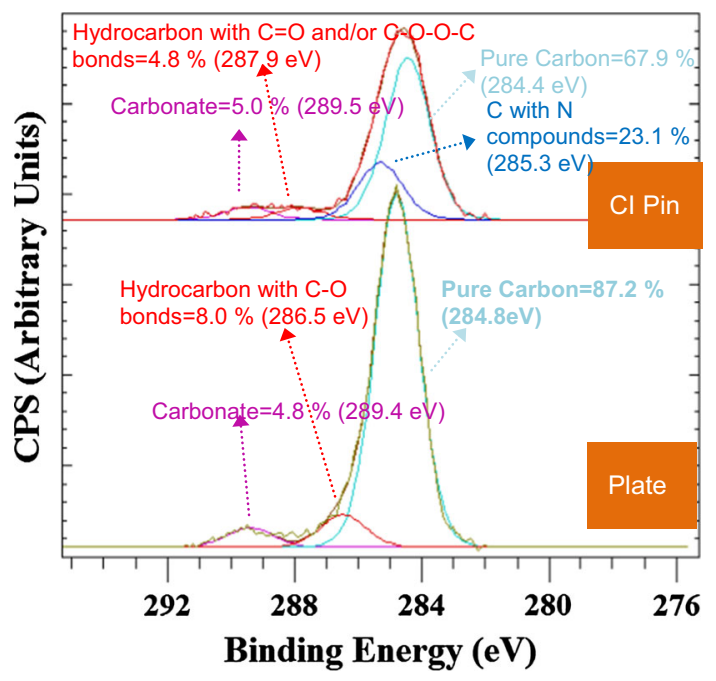

Fig. 10 Carbon species on the wear scar of the DLC coating and CI pins for the highest wear giving lubricants (Oil-)

lubricant components as compared to the DLC coating. Therefore, it appears that DLC wear debris could also contribute to the friction reduction along with the additivederived low-friction $\mathrm{MoS}_{2}$ sheets [10].

\subsection{DLC/Ceramic System}

As mentioned earlier, various authors have suggested different mechanisms by which MoDTC induces high wear to DLC coatings. It was suggested that the formation of hard Mo compounds on the steel counterpart accelerates the wear of the DLC plate when lubricated in oils containing MoDTC [6] and that MoDTC-induced wear was not seen in the DLC/DLC contacts [11]. For this part of the experiments, the lubricant which gave higher wear (Oil-) to the DLC/CI combination was used. Tribo-tests were conducted for $20 \mathrm{~h}$ using silicon nitride balls which are known to be inert. This could potentially hinder the formation of hard Mo compounds on the counterpart surface. The hardness of the ceramic balls was in the range of $14-17 \mathrm{GPa}$ as opposed to 4-4.5 GPa for the CI pins (see Table 2 for the full description of the materials used). The high hardness of the ceramic ball could mitigate the formation of "microsize" particles coming from the counterbody. Iron-derived debris may promote graphitisation, and thus high wear of the DLC surfaces by increasing the local pressure on the DLC surface [8, 14].

\subsubsection{Friction Results}

Figure 11 displays the friction traces produced by the lower friction/higher wearing oil (i.e. Oil-) using two different counterparts when rubbed against the DLC coating. The friction trace for the DLC/CI system using Oil- is redrawn here for comparison purposes. Interestingly, using the same test parameters, no drop in friction was observed when the counterpart was ceramic while a significant friction reduction was evident using the CI pin.

The average friction coefficients for the last hour of the tests for the two different counterparts using Oil- are shown in Fig. 12. It is clear that the friction coefficient for the CI pin was almost 1.5 times lower than the ceramic ball.

\subsubsection{Wear Results}

Figure 13 shows a representative optical microscopic 3D image of the wear scar on the DLC coating when rubbed against ceramic when tested with Oil-. It is clear that using the ceramic counterpart, there was barely any measurable wear on the plate while high wear was seen using the same oil with CI pins (see Fig. 4).

EDX mapping of the DLC coating when rubbed against the ceramic counterpart is shown in Fig. 14. Based on the EDX mapping results, it is clear that using the ceramic ball, no difference in carbon or chromium intensity are seen comparing inside and outside the wear scar, confirming the 
Fig. 11 Friction traces as a function of time using different counterpart on the DLC-coated plate lubricated in Oil-

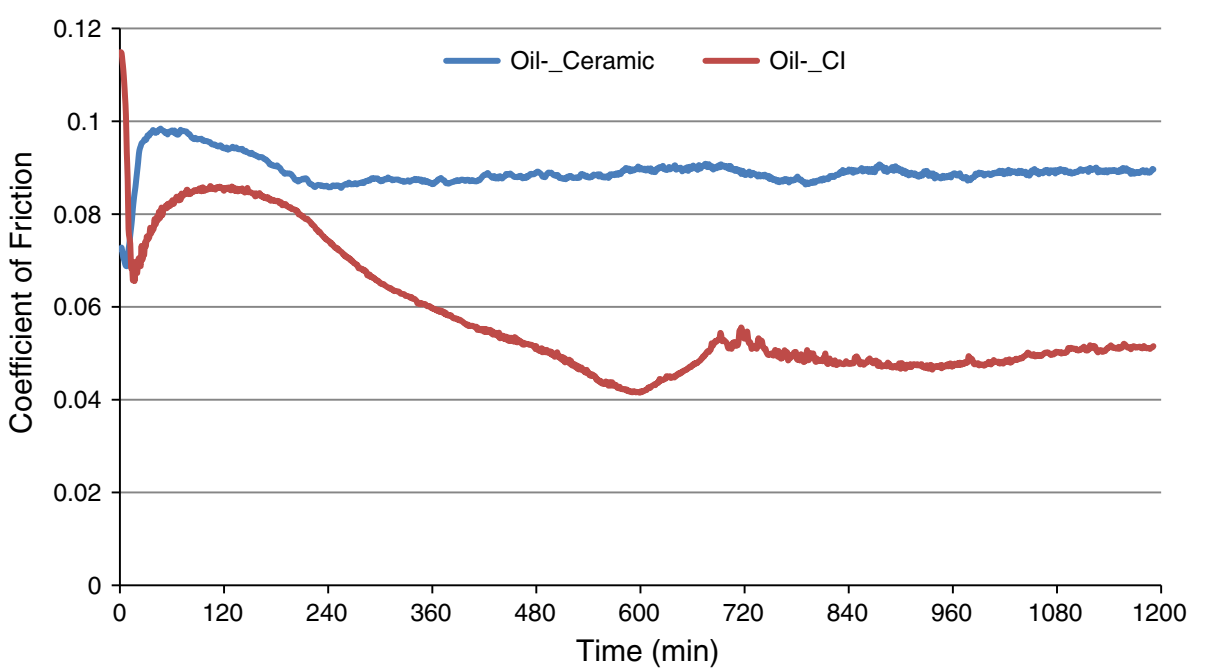

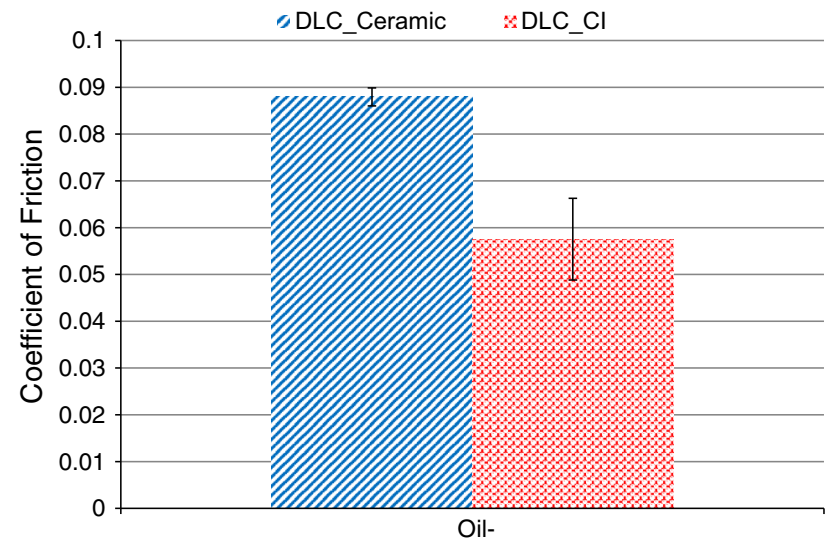

Fig. 12 Average coefficient of friction for the last hour of the tests as a function of Oil- using different counterpart materials on the DLCcoated plate. Standard deviation is obtained from three repeated tests

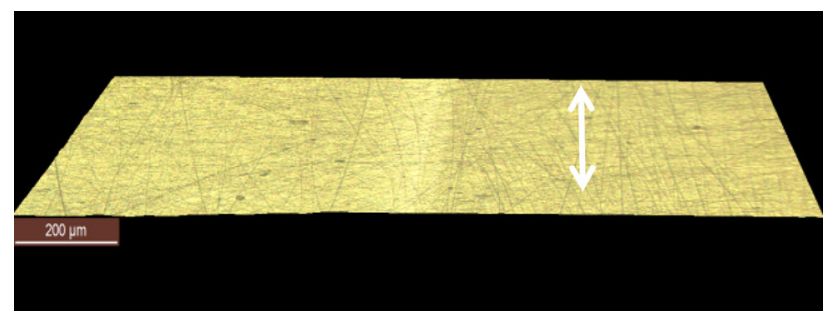

Fig. 13 Optical images of the wear scars formed on the DLC-coated plate when rubbed against the ceramic ball lubricated with Oil- lack of noticeable wear on the coated plates when rubbed against ceramic balls.

\subsubsection{Chemical Analysis of the Tribofilm}

XPS analysis was also performed on the DLC coating when rubbed against ceramic balls using the highest wear giving oil (Oil-). Figure 15 shows the survey scans of the DLC wear scar when rubbed against CI pins and ceramic balls. The XPS elemental quantification of the tribofilms formed on DLC wear scars (Table 4) shows that additive-derived elements were present in the tribofilm irrespective of the counterpart type. However, $\mathrm{Fe} 2 \mathrm{p}$ and $\mathrm{Cr} 2 \mathrm{p}$ peaks were only detected in the DLC tribofilm for the DLC/CI system suggesting severe wear/delamination of the DLC coating (20 h test using Oil-) only using cast iron counterpart.

It is clear that tribofilms formed on the coating were rich in carbon for both the DLC/ceramic and the DLC/CI system (see Table 3f), whereas a minor portion of the tribofilm is formed from the additives in the oil. More additive-derived elements were detected on the DLC in the DLC/CI system compared to the DLC/ceramic system. For instance, MoDTC decomposed and took part in the film formation on the DLC coating using both CI and ceramic ball. However, Mo $3 \mathrm{~d}$ peak was more dominant in the tribofilm formed on the DLC coating when rubbed against CI (see Fig. 15).

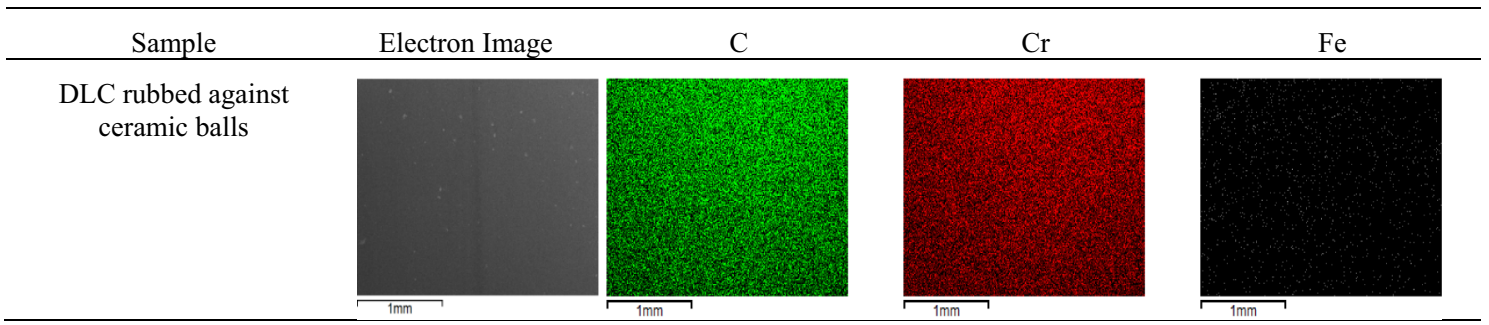

Fig. 14 SEM image of the DLC coating along with EDX mapping of the $\mathrm{C}, \mathrm{Cr}$ and $\mathrm{Fe}$ atoms lubricated with Oil- using ceramic balls 


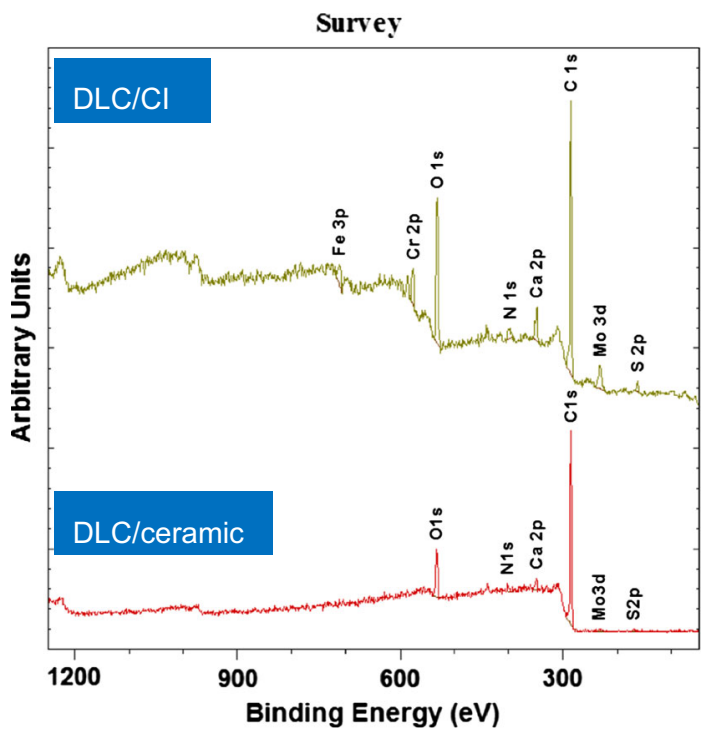

Fig. 15 Survey scan obtained from inside the DLC coating wear scar when rubbed against CI (top) and ceramic (bottom) using Oil-

Figure 16 shows the deconvoluted Mo 3d peaks obtained from the tribofilm formed on the DLC surface. It is evident that, for the DLC/CI, MoDTC-derived $\mathrm{MoS}_{2}$ and $\mathrm{MoO}_{3}$ formed on the DLC coating. In the case of the DLC/ ceramic system, binding energy of $229.6 \mathrm{eV}$ corresponds to formation of $\mathrm{Mo}^{4+}$ compounds such as $\mathrm{MoO}_{2}$ or $\mathrm{MoS}_{2}$ and binding energy of $233.2 \mathrm{eV}$ corresponds to $\mathrm{Mo}^{6+}$ compounds such as $\mathrm{MoO}_{3}$. Nevertheless, the amount of molybdenum compounds detected in the tribofilm of the DLC in the DLC/CI formed from Oil- is higher compared to the DLC/ceramic system.

\subsection{Mechanical Properties of the Coatings}

Nano-indentation tests were conducted within the worn areas of the DLC-coated surfaces as well as outside the wear scar for each sample. Table 5 summarizes the hardness and reduced elastic modulus $\left(\mathrm{E}_{\mathrm{r}}\right)$ values for the DLCcoated samples when rubbed against CI pins $(6,12$ and $20 \mathrm{~h}$ tests) and the ceramic ball ( $20 \mathrm{~h}$ test). The reduced modulus is calculated by combining the elastic modulus and Poisson's ratio of the indenter and the sample being indented. The coating thickness of the sample with the highest wear was measured to be around $1 \mu \mathrm{m}$, as shown in Fig. 7. In all cases, the depth of penetration for nano-indentation analysis was chosen to be around the $10 \%$ of the remaining coating thickness inside the wear scar to rule out

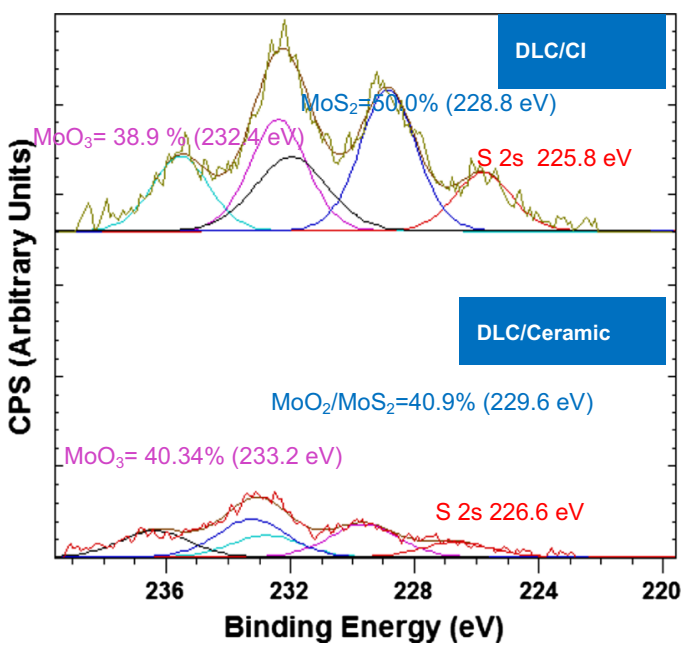

Fig. 16 Curve fitting of Mo 3d peaks obtained from tribofilm formed from Oil- on the DLC coating using CI pin (top) and ceramic ball (bottom)

the effect of substrate on the obtained measurements $[17,18]$.

For $6 \mathrm{~h}$ tests, using both oils, regardless of the extent of DLC wear and considering the standard deviation, the hardness and modulus of elasticity values were comparable with those of the as-deposited coating (H $19 \mathrm{GPa}$ and $\mathrm{Er}$ $170 \mathrm{GPa}$ ) (see Table 5a, b).

For Oil-, $\mathrm{H}$ and Er values decreased for the $12 \mathrm{~h}$ tests, indicating that the lubricant chemistry could have had an effect on coating mechanical properties and that surface modification/graphitisation of the DLC coating occurred after $12 \mathrm{~h}$ when lubricated by Oil- (Table $5 \mathrm{c}, \mathrm{d}$ ).

For $20 \mathrm{~h}$ tests, using both oils, DLC coatings generally showed decreased hardness and modulus of elasticity compared to the original properties (see Table 5e, f). To minimise the effect of substrate on hardness measurement for the coating, the indentation depth was kept at around $10 \%$ of the remaining coating thickness (around $100 \mathrm{~nm}$ penetration on a $1-\mu \mathrm{m}$-thick coating). Hence, the high coating wear observed for the $20 \mathrm{~h}$ test could be due to the changes in the mechanical properties of the coating.

In addition, the hardness and reduced elastic modulus values obtained from outside the wear scar (for all samples) were found to be very close to that of the as-deposited coating. This indicates that the wear mechanisms of DLC coatings requires a shearing/rubbing element (i.e. tribochemical effect) and cannot occur only via chemical reaction of the oils with the DLC coating.
Table 4 XPS quantification of tribofilms on the DLC coating for the DLC/CI and the DLC/ ceramic systems

\begin{tabular}{llllllll}
\hline Sample & O 1s $\%$ & C 1s $\%$ & Ca 2p $\%$ & Mo $\%$ & N 1s $\%$ & S 2p \% & Fe 2p \% \\
\hline DLC/CI & 9.1 & 76.5 & 1.6 & 6.9 & 4.1 & 1.4 & 0.3 \\
DLC/ceramic & 4.9 & 89.0 & 0.8 & 3.1 & 1.7 & 0.5 & 0.0 \\
\hline
\end{tabular}


Table 5 Nano-scale mechanical properties of DLC coating rubbed against CI for (a) Oil+ after 6 h, (b) Oil- after 6 h, (c) Oil+ after 12 h, (d) Oil- after $12 \mathrm{~h}$, (e) Oil+ after $20 \mathrm{~h}$, (f) Oil- after $20 \mathrm{~h}$ (g) Oil- after $20 \mathrm{~h}$ tribo-tests rubbing against ceramic

\begin{tabular}{|c|c|c|c|c|c|c|c|}
\hline Sample & Measurement position & $\begin{array}{l}\text { Maximum } \\
\text { depth (nm) }\end{array}$ & $\begin{array}{l}\text { Standard } \\
\text { deviation }( \pm)\end{array}$ & $\begin{array}{l}\text { Hardness } \\
(\mathrm{GPa})\end{array}$ & $\begin{array}{l}\text { Standard } \\
\text { deviation }( \pm)\end{array}$ & $\begin{array}{l}\text { Reduced elastic } \\
\text { modulus (GPa) }\end{array}$ & $\begin{array}{l}\text { Standard } \\
\text { deviation }( \pm)\end{array}$ \\
\hline \multirow[t]{2}{*}{ (a) } & Inside wear track & 107.0 & 6.3 & 16.5 & 1.9 & 140.8 & 8.2 \\
\hline & Outside wear track & 115.9 & 12.5 & 18.4 & 4.6 & 167.4 & 28.9 \\
\hline \multirow[t]{2}{*}{ (b) } & Inside wear track & 96.4 & 7.0 & 19.0 & 2.6 & 176.0 & 15.4 \\
\hline & Outside wear track & 97.8 & 13.1 & 19.4 & 5.4 & 177.7 & 39.8 \\
\hline \multirow[t]{2}{*}{ (c) } & Inside wear track & 93.3 & 6.1 & 20.7 & 2.0 & 180.8 & 8.8 \\
\hline & Outside wear track & 94.2 & 15.8 & 22.3 & 8.0 & 192.1 & 50.5 \\
\hline \multirow[t]{2}{*}{ (d) } & Inside wear track & 96.7 & 6.2 & 12.4 & 2.7 & 150.4 & 9.8 \\
\hline & Outside wear track & 103.9 & 13.31 & 16.4 & 4.9 & 165.3 & 37.9 \\
\hline \multirow[t]{2}{*}{ (e) } & Inside wear track & 80.9 & 14.4 & 10.7 & 2.2 & 129.6 & 11.1 \\
\hline & Outside wear track & 100.6 & 10.9 & 23.3 & 5.2 & 198.4 & 33.4 \\
\hline \multirow[t]{2}{*}{ (f) } & Inside wear track & 77.4 & 16.0 & 10.9 & 1.6 & 140.3 & 9.3 \\
\hline & Outside wear track & 105.1 & 9.4 & 20.9 & 4.9 & 186.4 & 26.1 \\
\hline \multirow[t]{2}{*}{ (g) } & Inside wear track & 111.5 & 4.72 & 18.2 & 1.7 & 170.6 & 11.3 \\
\hline & Outside wear track & 115.6 & 11.6 & 17.2 & 3.2 & 165.8 & 24.5 \\
\hline
\end{tabular}

For the $20 \mathrm{~h}$ tests, using Oil- (high wear), no evidence of the DLC surface modification was observed in the DLC/ ceramic system and the mechanical properties (i.e. hardness and Young's modulus) of the worn area were in the range of the as-deposited coating (see Table 5).

\section{Discussion}

\subsection{Effect of Lubricant Additives on Tribological Performance of the DLC Coating}

\subsubsection{Effect of Counterpart: Low-Friction Film Formation}

In the literature, the presence of a ferrous counterface was thought to play a role in MoDTC-induced wear of the DLC coating by promoting the formation of $\mathrm{MoO}_{3}$ [11], or generating iron oxide particles in the DLC/steel interface. Iron oxide/iron debris may produce high local pressures [8] on the DLC surface leading to high wear of the coating. In addition, increased hardness of the ferrous counterpart by the formation of hard Mo compounds on the steel surface was suggested to be a possible mechanism for wear acceleration of the DLC coating in the presence of MoDTC [6]. It is evident that the tribofilms formed from both Oil+ and Oil- on the CI pin were generally richer in $\mathrm{MoS}_{2}$ for 12-h sample than 6- and 20-h test samples, resulting in the lowest friction coefficient observed. In the DLC/CI system, friction values initially decreased due to the formation of lowfriction $\mathrm{MoS}_{2}$ tribofilm on the interface followed by modification/graphitisation of the DLC coating. Further sliding (20 h tests) showed both friction and wear to increase. The high wear of the DLC is shown to lead to a new interface (CrN/CI), and as a result increased friction at longer rubbing times (Fig. 3). This observation is in agreement with the friction results obtained by testing another type of DLC with $\mathrm{CrN}$ as an interlayer [23]. It appears that the rubbing process results in significant intensity change of Mo detected on the wear scar on both pin and coating (Table 3), resulting in carbon layer wear and friction increase. In addition, the formation and depletion of the tribofilm could be responsible for the changes observed in the friction response. It appears that reduction in friction in the DLC/CI system came at the cost of significant wear of the hydrogenated DLC. Furthermore, high wear of the DLC coating resulted in the transfer of the DLC's worn material to the CI pin. The presence of $s p^{2}$ carbon bonds in the DLC coating matrix provides them with inherently low-friction properties. Therefore, the transfer layer of the DLC coating, as evidenced by the XPS analysis, may consist of the low shear strength $\mathrm{sp}^{2}$-dominated graphitic carbon. Therefore, it appears that a combination of MoDTC-derived $\mathrm{MoS}_{2}$ species along with DLC wear debris facilitated friction reduction for the DLC/CI tribocouple. This is in agreement with a recent study [24] where a mixture of additive- and DLC-derived products was found to be responsible for the tribological behaviour of the DLC/steel system. In Fig. 17, the mechanism of low-friction film formation on the DLC coating is schematically compared with that of the uncoated steel surface. Figure 17, shows that the friction reduction on the DLC surface is influenced by both the low-friction $\mathrm{MoS}_{2}$ and the low-friction DLC wear debris whereas on the steel surfaces, low-friction $\mathrm{MoS}_{2}$ species were the dominating factor for the friction performance [10]. 
Fig. 17 Schematic diagram of low-friction film present at the interface in the: a steel/CI [10] and $\mathbf{b}$ DLC/CI systems
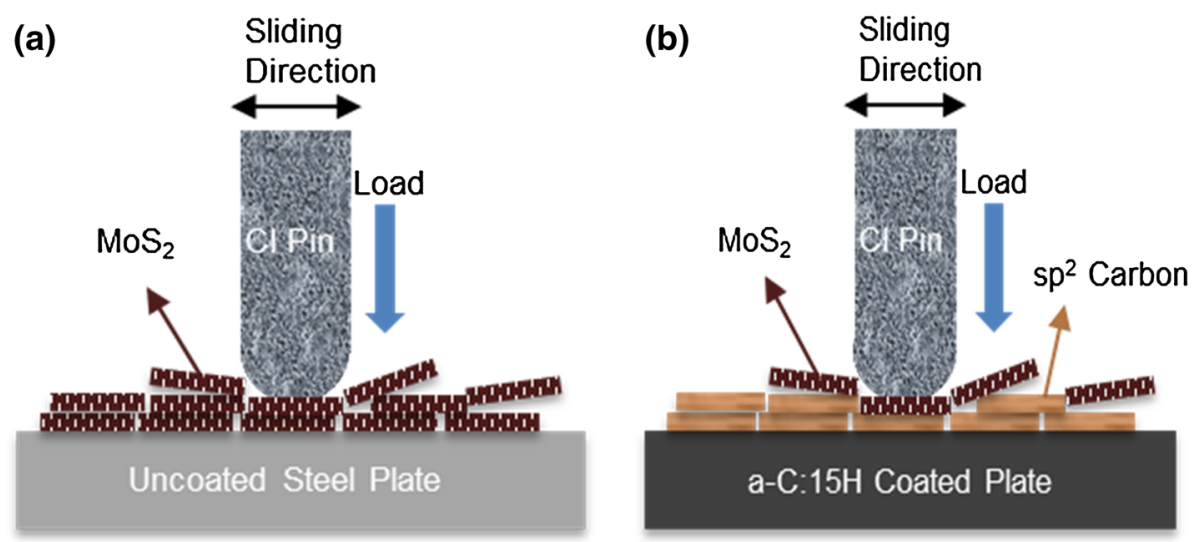

In the DLC/ceramic system, the MoDTC friction modifier in the oil did not reduce the friction as seen with the CI counterpart, although $\mathrm{MoS}_{2}$ and $\mathrm{MoO}_{3}$ were detected on the wear scar (Table 4; Fig. 16). Also, no significant wear was measured on the DLC plate. The presence of the MoDTC tribofilm on the coating wear scar, while wear was low, indicates that the high coating wear is accelerated by the ferrous counterpart, in agreement with literature [11].

\subsubsection{Effect of Counterpart: Anti-Wear Film Formation}

The positive effect of ZDDP in reducing the MoDTC-induced wear seen in this study is in agreement with previous work [9]. However, this effect was less pronounced for long $(20 \mathrm{~h})$ tests. Similarly, Haque et al. [4] reported that the addition of ZDDP to a MoDTC-containing base oil could suppress the adverse effect of MoDTC in giving high wear to the DLC coating in the DLC/steel system [4]. In this study, XPS analysis evidenced the formation of ZDDPderived tribofilm on both DLC-coated plates and CI pins when lubricated in Oil+. ZDDP-derived glassy phosphate species protect the surface against excessive wear as well as minimise the formation of iron oxide particles. Iron oxide particles were reported to promote modification, and as a result wear, of the DLC coating by exerting higher local pressures [8]. ZDDP could also act as an oxidation inhibitor $[21,25,26]$ and hinder the formation of $\mathrm{MoO}_{\mathrm{x}}(\mathrm{a}$ possible cause of DLC brittleness in MoDTC-containing oils [5]) or promotes the formation of iron sulphide leading to a reduction of the iron oxide formation. Further study is required to establish the exact link between Mo-containing friction modifiers and the wear of DLC and the role of ZDDP in this mechanism.

\subsubsection{Nano-indentation: Effect of Lubricant and Sliding}

The nano-indentation study suggested that, using both oils, the mechanical properties of the DLC coating was modified when rubbed against $\mathrm{CI}$ pins and that the coating became softer (i.e. inside the wear scar) than the as-received coating. It should be noted that there is some variability of the nano-hardness outside the wear scar probably due to the inherent coating variability and the effects of thermally derived films. Figure 18 shows the coefficient of wear and hardness variation with time for the DLC/CI and the DLC/ ceramic combinations when lubricated in Oil-. It is clear that using CI pins, wear showed an inverse relationship with hardness of the coating, i.e. the higher the coating wear, the lower the hardness, and vice versa. In contrast, for the DLC/ceramic combinations, the hardness of the DLC coating was in the range of hardness values for the asdeposited coating after $20 \mathrm{~h}$ tests. The obtained results do not contradict the findings by Sugimoto et al. [6] but suggest that graphitization/surface modification of DLC did not occur when the counterpart was ceramic. Experiments with the hard ceramic counterpart in this study rule out the effect of increase in the hardness of the steel counterpart (by formation of molybdenum compounds on the steel

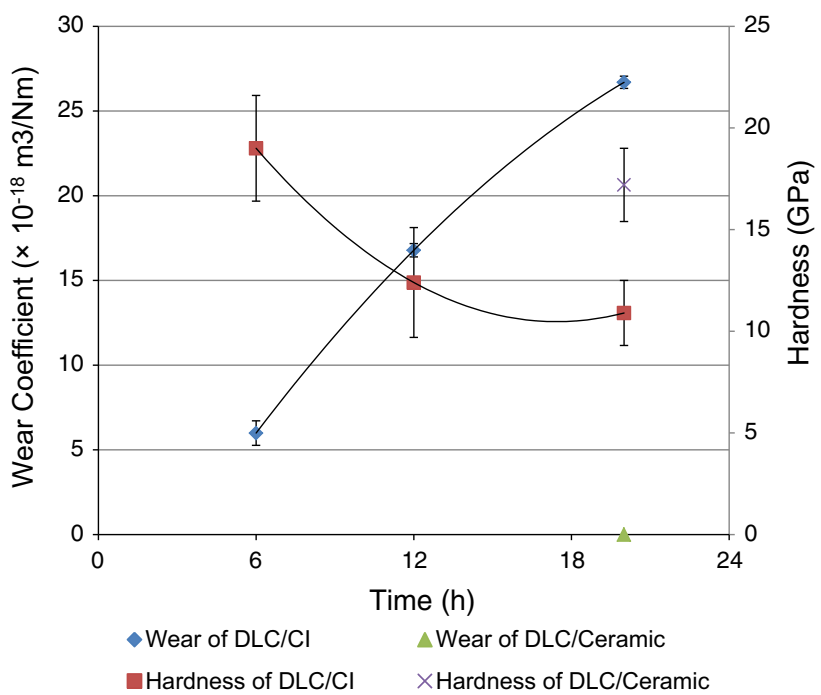

Fig. 18 Wear and hardness variation with time using DLC/CI and DLC/ceramic systems using Oil- 
counterpart surface as reported by Sugimoto et al. [6]) to be solely responsible for MoDTC-induced wear of the DLC coating.

Based on the observations of this study and the published literature [4-13], it is reasonable to assume that MoDTC decomposition products are playing a great role in giving this high wear to the hydrogenated DLC and that the presence of a steel counterpart is essential for such high wear.

\subsection{Mechanism of MoDTC-Induced Wear of DLC}

Despite several proposed mechanisms $[5,6,11]$ for the DLC high wear in oils containing MoDTC, there have been no clear explanations for such a phenomenon. The coating wear is believed to be accelerated by molybdenum-containing compounds since high DLC wear is not observed in tests with base oil [11]. Furthermore, formation of the molybdenum-containing compounds, believed to be responsible for high DLC wear, is promoted by the ferrous counterpart. This would explain why there was minimal wear, and no friction reduction, when DLC was tested with a ceramic counterpart. Generally, one or combination of the following mechanisms can be expected for the DLC wear process: (1) MoDTC-derived $\mathrm{MoO}_{3}$ or iron oxide particles from the ferrous counterpart promote abrasive wear of the DLC coating, (2) moly-oxides (molybdates) formed under tribological conditions [22] act as the catalyst for oxidation of or/and dehydrogenation of the DLC coating [27].

Taking into account the results from this study and previous studies in the literature, it is highly unlikely that all abrasive wear mechanism can be solely responsible for high wear of the DLC coating in DLC/ferrous contacts. In the study by Vengudusamy et al. [11], wear was comparable in both the a-C:H/a-C:H and the a-C:H/steel contacts when tests were conducted in the base oil. It can be argued that if DLC wear was only due to abrasive wear by iron oxides from the ferrous counterpart, then DLC wear would have been higher in the a-C:H/steel contact. However, comparable wear in the a-C:H/a-C:H and the a-C:H/steel contacts indicated that iron oxides at the tribocontact did not accelerate DLC wear. In this study, it was shown that in tests with lubricants containing MoDTC, although the amount of $\mathrm{MoO}_{\mathrm{x}}$ which was formed on the DLC plate was small for the DLC/ceramic system as compared to the DLC/CI tribocouple, $\mathrm{MoO}_{\mathrm{x}}$ species were formed in both contacts. This is in line with a previous study where $\mathrm{MoO}_{\mathrm{x}}$ species were found in tribofilms formed on both the a-C:H/ $\mathrm{a}-\mathrm{C}: \mathrm{H}$ and the a-C:H/steel contacts [11]. If DLC wear was only due to abrasive wear by $\mathrm{MoO}_{\mathrm{x}}$, wear of the DLC coating would have been comparable in contacts with ferrous and non-ferrous counterparts. Furthermore, DLC is a hard coating and not likely to be worn out by abrasive $\mathrm{MoO}_{\mathrm{x}}$ species.

On the other hand, it is possible that the iron molybdate formed from MoDTC decomposition in a ferrous tribological system accelerates DLC wear by breaking the $\mathrm{C}-\mathrm{C} /$ $\mathrm{C}-\mathrm{H}$ bonds in the coating. Iron molybdates are examples of molybdenum compounds formed on ferrous substrates that would otherwise not form on non-ferrous contacts. Iron molybdates are mostly used as catalysts in oxidation of hydrocarbons [27]. That could also explain high wear of the hydrogen-free DLC reported in [11]. There is also a possibility that the high DLC wear observed in the DLC/ferrous contacts was due to dehydrogenation of the DLC. Subsequent removal of the hydrogen in the DLC matrix could cause the carbon matrix to evolve towards a more graphitic structure [5]. This is also in line with our observation in this study where the coating in the wear scar became softer than the as-received coating with oils containing a high level of MoDTC.

The mechanisms leading to low friction and high wear, induced by MoDTC in the DLC/CI system, are then proposed (schematically shown in Fig. 19) as follows:

1. Molybdenum-containing species (moly-oxides) formed under tribological conditions could act as a catalyst for oxidation or/and dehydrogenation of the DLC coating. This will eventually lead to high wear of the DLC coating.

2. Wear debris formed from ferrous counterparts (cast iron pins) can promote formation of molybdenumcontaining species (i.e. iron molybdates) leading to a continuous process as described in point 1 . The addition of ZDDP will potentially limit the formation

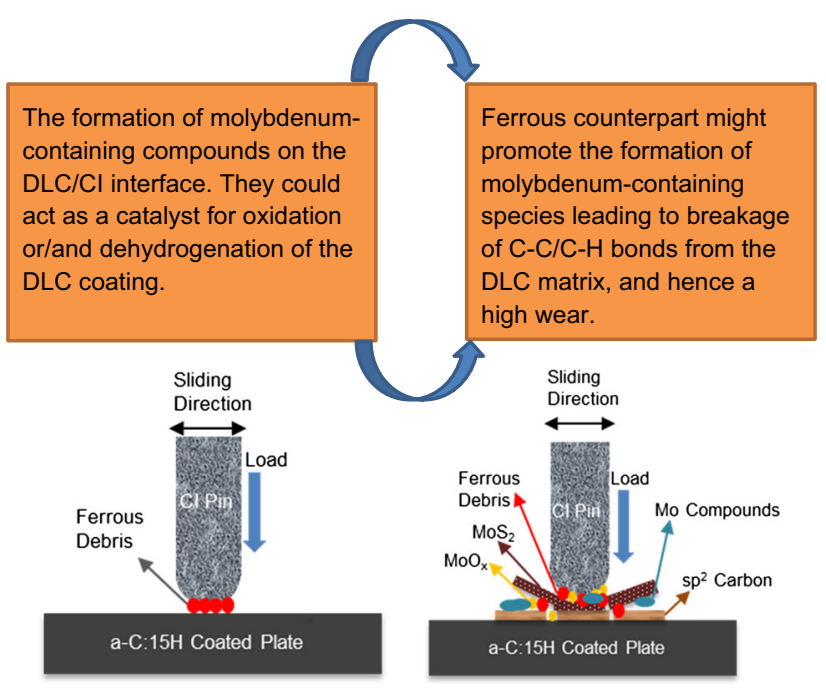

(1)

(2)

Fig. 19 Schematic diagram showing the MoDTC-induced wear mechanisms. (1) and (2) represent the first and the second stage of the proposed wear mechanisms 
of these wear debris (and a reduced catalytic effect from the iron surface) or promote the formation of iron sulphides rather than iron molybdates leading to reduction of these molybdates and hence reduced coating wear.

To verify the presence of Fe-Mo compounds at the contact, a combination of other chemical characterisation techniques beside XPS is necessary. Raman spectroscopy is particularly helpful in distinguishing molybdenum compounds with similar Mo oxidation states which would otherwise be difficult in XPS analysis. Further studies should therefore focus on investigating the chemical species formed when ferrous counterparts are used against DLC coatings in tests with MoDTC-containing lubricants.

\section{Conclusions}

This study provides some insights into hydrogenated DLC tribological performance in boundary lubrication. In summary, the key conclusions made from this work are:

- MoDTC concentration in a fully formulated oil will significantly affect the DLC coating wear when tested with a ferrous counterface.

- Formation of MoDTC tribofilm was responsible for both friction reduction and high wear of the DLC coating.

- The iron interaction with lubricant additives, especially MoDTC, accelerates the DLC coating wear. The formation of molybdenum-containing compounds in the presence of ferrous counterparts could lead to oxidation and accelerated DLC coating wear.

- ZDDP might hinder the MoDTC potency in giving high wear to DLC in the DLC/ferrous combinations by: (a) reducing the number of iron particles which might act as a catalyst for the oxidation of the MoDTC or/and (b) blocking the reactive sites on the iron by preferentially forming iron sulphides.

Open Access This article is distributed under the terms of the Creative Commons Attribution 4.0 International License (http://crea tivecommons.org/licenses/by/4.0/), which permits unrestricted use, distribution, and reproduction in any medium, provided you give appropriate credit to the original author(s) and the source, provide a link to the Creative Commons license, and indicate if changes were made.

\section{References}

1. Grossiord, C., Varlot, K., Martin, J.M., Le Mogne, T., Esnouf, C., Inoue, K.: MoS2 single sheet lubrication by molybdenum dithiocarbamate. Tribol. Int. 31(12), 737-743 (1998)
2. Morina, A., Neville, A., Priest, M., Green, J.H.: ZDDP and MoDTC interactions and their effect on tribological performance-tribofilm characteristics and its evolution. Tribol. Lett. 24(3), 243-256 (2006). doi:10.1007/s11249-006-9123-7

3. De Barros, M.I., Bouchet, J., Raoult, I., Le Mogne, T., Martin, J.M., Kasrai, M., Yamada, Y.: Friction reduction by metal sulfides in boundary lubrication studied by XPS and XANES analyses. Wear 254(9), 863-870 (2003)

4. Haque, T., Morina, A., Neville, A.: Influence of friction modifier and antiwear additives on the tribological performance of a nonhydrogenated DLC coating. Surf. Coat. Technol. 204(24), 4001-4011 (2010)

5. Shinyoshi, T., Fuwa, Y., Ozaki, Y.: Wear analysis of DLC coating in oil containing Mo-DTC. SAE Technical Paper 2007-01-1969. (2007). doi:10.4271/2007-01-1969

6. Sugimoto, I.: Mechanism on specific wear of DLC film in engine oil with Mo-DTC. Trans. Jpn. Soc. Mech. Eng. Ser. A 78(786), 213-222 (2012)

7. Haque, T., Morina, A., Neville, A.: Tribological performance evaluation of a hydrogenated diamond-like carbon coating in sliding/rolling contact—effect of lubricant additives. Proc. Inst. Mech. Eng. Part J J. Eng. Tribol. 225(6), 393-405 (2011). doi:10. 1177/1350650111402769

8. Haque, T., Morina, A., Neville, A., Kapadia, R., Arrowsmith, S.: Effect of oil additives on the durability of hydrogenated DLC coating under boundary lubrication conditions. Wear 266(1-2), 147-157 (2009)

9. Kosarieh, S., Morina, A., Lainé, E., Flemming, J., Neville, A.: The effect of MoDTC-type friction modifier on the wear performance of a hydrogenated DLC coating. Wear 302(1-2), 890-898 (2013)

10. Haque, T., Morina, A., Neville, A.: Effect of friction modifiers and antiwear additives on the tribological performance of a hydrogenated DLC coating. J. Tribol. Trans. ASME 132(3), 032101 (2010). doi:10.1115/1.4001650

11. Vengudusamy, B., Green, J.H., Lamb, G.D., Spikes, H.A.: Behaviour of MoDTC in DLC/DLC and DLC/steel contacts. Tribol. Int. 54, 68-76 (2012)

12. Masuko, M., Ono, T., Aoki, S., Suzuki, A., Ito, H.: Friction and wear characteristics of DLC coatings with different hydrogen content lubricated with several Mo-containing compounds and their related compounds. Tribol. Int. 82(Part B), 350-357 (2015). doi:10.1016/j.triboint.2014.04.037

13. De Feo, M., De Barros Bouchet, M.I., Minfray, C., Le Mogne, T., Meunier, F., Yang, L., Thiebaut, B., Martin, J.M.: MoDTC lubrication of DLC-involving contacts. Impact of MoDTC degradation. Wear 348-349, 116-125 (2016). doi:10.1016/j.wear. 2015.12.001

14. Kosarieh, S., Morina, A., Lainé, E., Flemming, J., Neville, A.: Tribological performance and tribochemical processes in a DLC/ steel system when lubricated in a fully formulated oil and base oil. Surf. Coat. Technol. 217, 1-12 (2013)

15. Hamrock, B.J., Dowson, D.: Ball Bearing Lubrication : The Elastohydrodynamics of Elliptical Contacts. Wiley, New York (1981)

16. Stachowiak, G.W., Batchelor, A.W.: Elastohydrodynamic lubrication. In: Engineering Tribology, 3rd edn. pp. 287-362. Butterworth-Heinemann, Burlington (2006)

17. Kramer, D.E., Volinsky, A.A., Moody, N.R., Gerberich, W.W.: Substrate effects on indentation plastic zone development in thin soft films. J. Mater. Res. 16(11), 3150-3157 (2001)

18. Fischer-Cripps, A.C.: Review of analysis methods for sub-micron indentation testing. Vacuum 58(4), 569-585 (2000)

19. Fairley, N.: CasaXPS VAMAS processing software. Available from World Wide Web: http://www.casaxps.com. (2010) 
20. Moulder, J.F., Bomben, K.D., Sobol, P.E., Stickle, W.F.: Handbook of X-Ray Photoelectron Spectroscopy. A Reference Book of Standard Spectra for Identification and Interpretation of XPS Data. Physical Electronics, Eden Prairie (1992)

21. Spikes, H.: The history and mechanisms of ZDDP. Tribol. Lett. 17(3), 469-489 (2004)

22. Khaemba, D.N., Neville, A., Morina, A.: New insights on the decomposition mechanism of Molybdenum DialkyldiThioCarbamate (MoDTC): a Raman spectroscopic study. RSC Adv. 6(45), 38637-38646 (2016). doi:10.1039/C6RA00652C

23. Kalin, M., Vizintin, J.: Differences in the tribological mechanisms when using non-doped, metal-doped (Ti, WC), and nonmetal-doped $(\mathrm{Si})$ diamond-like carbon against steel under boundary lubrication, with and without oil additives. Thin Solid Films 515(4), 2734-2747 (2006)

24. Vengudusamy, B., Grafl, A., Preinfalk, K.: Tribological properties of hydrogenated amorphous carbon under dry and lubricated conditions. Diam. Relat. Mater. 41, 53-64 (2014). doi:10.1016/j. diamond.2013.11.009

25. Bovington, C., Castle, R.: Lubricant chemistry including the impact of legislation. In: Dowson, D., Priest, M., Dalmaz, G., Lubrecht, A.A. (eds.) Tribology Series, vol. 40, pp. 141-146. Elsevier, Amsterdam (2002)

26. Gellman, A.J., Spencer, N.D.: Surface chemistry in tribology. Proc. Inst. Mech. Eng. Part J J. Eng. Tribol. 216(6), 443-461 (2002)

27. Bowker, M., Brookes, C., Carley, A.F., House, M.P., Kosif, M., Sankar, G., Wawata, I., Wells, P.P., Yaseneva, P.: Evolution of active catalysts for the selective oxidative dehydrogenation of methanol on $\mathrm{Fe}_{2} \mathrm{O}_{3}$ surface doped with Mo oxide. Phys. Chem. Chem. Phys. 15(29), 12056-12067 (2013). doi:10.1039/ c3cp50399b 